\title{
Resolving London's bed crisis: there might be a way, is there the will?
}

\author{
Paul Lelliott, Bernard Audini and Nancy Darroch
}

The report of the first MILMIS (Monitoring Inner London Mental Illness Services) survey (pages 276-280) confirms the impression that there is a crisis in the capital's psychiatric services. It is the day to day happenings that underlie the MILMIS indicators that are most shocking; these were not captured directly by the survey but came in the form of anecdotes from participants. Some have been highlighted by other commentators (Watson, 1994; Hollander \& Slater, 1994). It is common for there to be no admission beds available at all in the South of England. In these circumstances patients, who may be highly distressed or disturbed, may have to be nursed for 24 or even 36 hours in a room in an accident and emergency department while doctors or nurses make numerous phone calls to locate a bed, often at a hospital many miles outside of London. There have been instances where suicidal or dangerous patients have absconded while waiting and others where patients, who would have accepted voluntary admission to their local unit, have had to be compulsorily admitted because they did not wish to go to the distant hospital.

While the immediate care of those admitted to distant hospitals may well be adequate, this situation makes a mockery of trust mission statements and commissioning plans that talk of local and accessible services and integration between hospital and community. While not advocating a return to the asylum, it would be difficult to argue that to admit a London resident to a hospital on the south coast is any advance from the days when such patients would have been admitted to the large psychiatric hospitals that ringed London; at least these hospitals had established channels of communication with the local facilities.

The MILMIS indicators that relate to ward conditions almost certainly reflect a vicious circle, part of which was described by the Audit Commission (1994). High admission thresholds and few beds concentrate severely ill people on acute units, creating a culture of violence and sexual harassment. Such living conditions are intolerable and not surprisingly many patients will not accept them; those who are not safe to be in the community therefore have to be compulsorily admitted to keep them in hospital (one half of patients were detained under the Mental Health Act; in one service the proportion was two-thirds). In this highly charged atmosphere, containment is the priority for staff, rather than therapy, rehabilitation and resettlement. This, coupled with inadequate community provision, particularly access to high staffed hostels, delays discharge and further blocks beds (Lelliott \& Wing, 1994).

Were service planners to design an environment for the treatment of people with schizophrenia on the basis of what is known about the social and environmental factors that contribute to health in such people, the results would certainly not resemble a London psychiatric admission ward. The MILMIS findings about conditions in hospital wards perhaps go some way to explaining why patients prefer community based alternatives to hospital care (Muijen et al, 1992).

Although the MILMIS indicators do not directly inform the debate as to how to resolve the problem for London services, most commentators agree that reducing bed occupancy levels would be an essential element to any plan, but how should this be achieved?

The debate has become polarised between those who advocate the apparently simple expedient of creating more beds (e.g. Watson, 1994) and those who hold that the solution lies in creating more effective community services 
that would lead to less need for beds (e.g. Audit Commission, 1994). There is consensus that increasing the range and availability of community-based residential provision (e.g. respite services and properly staffed hostels) as an alternative to hospitalisation may prevent some admissions and shorten others (Lelliott \& Wing, 1994). Upgrading and expanding accommodation in existing hospital wards to meet at least a minimal quality standard would be expensive. Inpatient care already accounts for over $75 \%$ of the budget for secondary mental health services. The alternative of attempting to replace some existing beds with community alternatives would not be cheaper and may not now be possible from the NHS mental health budget. Each option, or a combination of both, requires the creation of new and better facilities for people with longer-term disability.

The history of mental health funding shows that bed closures have not in the past released large sums for community developments (Lelliott et al, 1993) and the opportunity to do this has now almost certainly been missed (Wing \& Lelliott, 1994), even were bridging finance made avallable (Audit Commission, 1994). The research evidence suggests that services that work actively to minimise lengths of stay, and have integrated and comprehensive hospital and communitybased faclities, can reduce the use of inpatient beds by $20 \%$ to $40 \%$ (Thornicroft $\&$ Strathdee, 1994). If the upper figure applied across inner London, average bed occupancy would reduce to only about $85 \%$, the figure generally accepted as optimal (Royal College of Psychiatrists, 1993). The MILMIS results therefore support the view that it might now be too late to move money from beds to community.

How then could the bed crisis be resolved? First, all parties would have to agree that the state of in-patient services is the most pressing issue for mental health services in London. Policy-makers, commissioners (particularly GP fund-holders), service managers and clinicians must adopt this as a common agenda. To do so would involve paying more than mere lip service to giving absolute priority to the patient group likely to need in-patient care. Money spent on funding extracontractural referrals to distant NHS or private hospitals must be ear-marked for developing local mental health services. In the absence of other new money, new developments to reduce bed use could only be made by diverting resources from patients with less severe illnesses. Thus provision such as out-patient clinics for new referrals from primary care, community psychiatric nurses working in primary care settings and psychotherapy services would have to be cut. Bed management strategles (Department of Health, 1994) and new services would have to be developed that maintained a focus on relieving pressure on in-patient services, and their continued funding be made dependent on a demonstration that they have had that effect. The MILMIS indicators provide reasonably robust measures to do this.

This course of action would be neither easy nor popular. Although all agree that 'something must be done' about the bed crisis, and there have been statements of good intent from politicians and commissioners, the true political will may be lacking. The government is committed to concentrating purchasing power with GP fund-holders who might not have the necessary altruism to agree to divert money from the less severe disorders, that afflict the bulk of their patients with mental illness. As the power balance shifts, the old health authorities will become driven increasingly by this primary care agenda.

Even if the political will existed, could provider units deliver the sort of high quality service that anecdotal and some experimental evidence suggests would reduce dependency on beds? Experimental assertive outreach and 24 hour crisis intervention teams are probably staffed by unusually enthusiastic, committed and well supervised people. There is disturbing anecdotal evidence that even these teams, which showed the potential of community alternatives, have struggled to survive the departure of the pioneering leaders who established them. There is certainly no proof that such models can be both replicated and sustained in 'average' services. Finally it must be acknowledged that many psychiatrists would balk at the prospect of working in 'psychosis-only' services (whether based chiefly on hospital or on community models) thus neglecting many of the skills they have acquired in treating people with less severe illnesses.

Media interest in the results of the first MILMIS survey was not confined to the London press. The project coordinators also recelved unsolicited correspondence from services outside of London, both rural and urban, reporting that they too had excessively high 
bed occupancy levels and difficulties in admitting acutely disturbed psychiatric patients. The problem reflected by the MILMIS results and the difficulties of addressing them may not just be a London one.

\section{References}

Audrr Commission (1994) Finding a Place: a review of mental health services for adults. London: HMSO.

DEPARTMENT OF HEALTH (1994) The Health of the Natton Key Area Handbook: Mental Iliness, 2nd Edition. London: HMSO.

HOLANDER, D. \& SLATER, M. S. (1994) 'Sorry, no beds': a problem for acute psychlatric admissions. Psychiatric Bulletin, 18, 532-534.

LELuOTT, P. \& Wing, J. (1994) National audit of new long-stay psychlatric patients. 2: Impact on services. Brtish Journal of Psychiatry. 165, 160-169.
-. Sims, A. \& WiNG, J. (1993) Who pays for community care? The same old question. Brtish Medical Joumal, s07. 991-994.

MULJEN, M., MArks, I. M., CONNOLLY, J. \& AUdin, B. (1992) Home based care and standard hospital treatment for patients with severe mental illness: A randomised trial. Brittsh Journal of Psychiatry. 160, 379-384.

THORNICROFT, G. \& STRATHDEE G. (1994) How many psychlatric beds. British Medical Journal, s09. 970-971. Watson, J. P. (1994) Too few beds. Psychiatric Bullettr, 18. 531.

WING, J. \& LeuroTt, P. (1994) Number of psychlatric beds needed. Brittsh Medical Journal, s09, 1516 (letter).

Paul Leluot, Director, Royal College of Psychiatrists' Research Unit, BERNARD AUDINI, Research Worker, Royal College of Psychiatrists' Research Unit, 11 Grosuenor Crescent, London SWIX 7EE, and NANCY DARROCH, Consultant Psychiatrist, Greenwich District Hospital, Vanbrugh Hill, London SE10 9HE

\section{Psychiatry in Europe Directions and Developments}

\section{Edited by Tom Sensky, Cornelius Katona \& Stuart Montgomery}

With the development of the European Union, psychiatrists in Britain are expanding their links with colleagues in continental Europe. This wide-ranging book discusses issues affecting modern psychiatric practice in Europe, such as legislative differences, collaborative projects and treatment priorities, as well as innovative techniques and research methods.

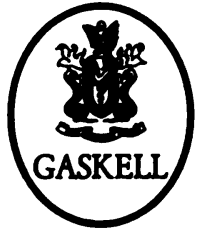

$\bullet £ 10.00 \bullet 199 p p . \bullet 1994 \bullet$ ISBN 0902241710

Available from the Publications Department, Royal College of Psychiatrists, 17 Belgrave Square,

London SW1X 8PG (Tel. 0171-235 2351) 